Viso - Cadernos de estética aplicada Revista eletrônica de estética

ISSN 1981-4062

No 12, jul-dez/2012

http://www.revistaviso.com.br/
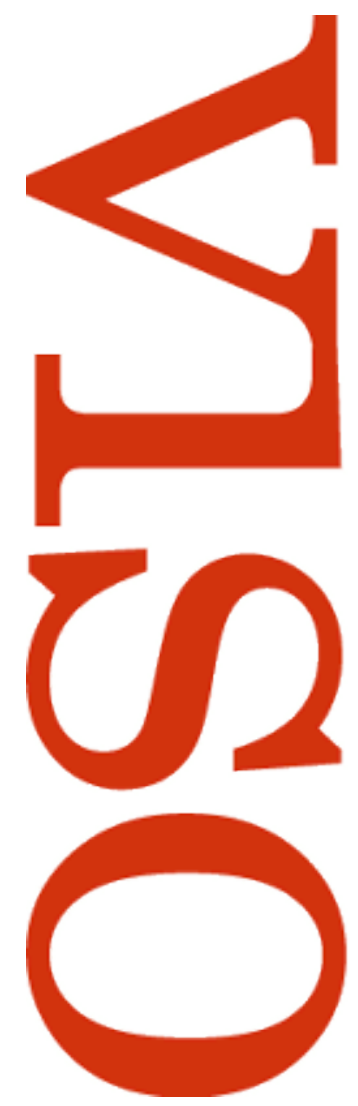

\title{
A educação estética de Hans Castorp: A montanha mágica como Bildungsroman \\ Pedro Caldas
}

Universidade Federal do Estado do Rio de Janeiro (UniRio)

Rio de Janeiro, Brasil 


\section{RESUMO}

\section{A educação estética de Hans Castorp: A montanha mágica como Bildungsroman}

Neste artigo, faço uma reflexão crítica sobre o romance $A$ montanha mágica (1924), de Thomas Mann, como um possível romance de formação. De acordo com Franco Moretti, o "Bildungsorman" é a forma simbólica da modernidade, porque é nela que a juventude se torna a parte mais significativa da vida, na medida em que incorpora o dinamismo e a instabilidade que tanto caracterizam a temporalidade moderna. A experiência da juventude pode ser uma das coisas perdidas depois da Primeira Guerra Mundial. Esta experiência é marcada por uma sensação de perda da capacidade de construir sentido, como Walter Benjamin articulou em seu famoso ensaio "Experiência e pobreza". De alguma maneira, a construção de um personagem jovem, como Hans Castorp (mesmo que ele tenha vivido antes da Guerra) implica um desafio formal. Qual foi a linguagem disponível para a construção de um personagem jovem naquele momento histórico específico? Neste artigo, defendo a ideia de que Hans Castorp, diferentemente de um Pip, de Charles Dickens, ou de um Rubempré, de Balzac, não se resigna nem se autodestrói. Ele é um personagem de romance de formação na medida em que se deixa educar esteticamente.

Palavras-chave: Bildungsroman - República de Weimar - Thomas Mann - A montanha mágica 


\section{ABSTRACT}

Hans Castorp's aesthetic education: The Magic Mountain as a

\section{Bildungsroman}

In this paper I reflect critically on Thomas Mann's novel The Magic Mountain (1924) as a possible Bildungsroman. According to Franco Moretti, the "Bildungsroman" is the symbolic form of modernity, because it is in it that youth that becomes the most significant part of life for incorporating the dynamism and instability that so much characterize modern temporality. The experience of youth could be one of the things lost after the First World War. This experience is marked by a sense of loss, the ability to construct meaning, as Walter Benjamin articulated in his famous essay, "Experience and Poverty". Somehow, the building of a young character, such as, Hans Castorp (even if he lived before the War), implies a formal challenge. What was the language available to construct a young character at that specific historical moment?

Keywords: Bildungsroman - Weimar Republic - Thomas Mann - The Magic Mountain 


\section{CALDAS, P. "A educação estética de Hans Castorp: $A$ montanha mágica como Bildungsroman". In: Viso: Cadernos de estética aplicada, v. VI, n. 12 (jul-dez/2012), pp. 128-150.}

DOI: 10.22409/1981-4062/v12i/146

Aprovado: 01.03.2013. Publicado: 13.07.2013.

(C) 2013 Pedro Caldas. Esse documento é distribuído nos termos da licença Creative Commons Atribuição-NãoComercial 4.0 Internacional (CC-BY-NC), que permite, exceto para fins comerciais, copiar e redistribuir o material em qualquer formato ou meio, bem como remixá-lo, transformá-lo ou criar a partir dele, desde que seja dado o devido crédito e indicada a licença sob a qual ele foi originalmente publicado.

Licença: http://creativecommons.org/licenses/by-nc/4.0/deed.pt_BR

Accepted: 01.03.2013. Published: 13.07.2013.

(C) 2013 Pedro Caldas. This document is distributed under the terms of a Creative Commons Attribution-NonCommercial 4.0 International license (CC-BY-NC) which allows, except for commercial purposes, to copy and redistribute the material in any medium or format and to remix, transform, and build upon the material, provided the original work is properly cited and states its license.

License: http://creativecommons.org/licenses/by-nc/4.0/ 
Minha motivação para pesquisar $A$ montanha mágica, de Thomas Mann, não se deu somente pelo prazer que sempre tive em ler a sua obra. Para ser sincero, a primeira leitura deste imenso romance publicado originalmente em 1924 não me envolveu tanto como Os Buddenbrooks, Morte em Veneza, Tonio Kröger e vários de seus contos. Alguns anos depois, a frieza seria substituída por uma leitura quase comovida. E suspeito que tanto a frieza como o sentimentalismo jamais deixariam de ser impressões imediatas e não elaboradas se não fosse a leitura de The Way of the World ${ }^{1}$, de Franco Moretti, um estudo sobre os romances de formação europeus no século XIX.

Não quero menosprezar estudos mais especializados², vários deles de alto nível, mas ficou difícil, nas leituras subsequentes do romance, não me lembrar de várias passagens e ideias de Moretti; assim como a releitura de The Way of the World, embora tenha me levado a querer ler absolutamente todos os romances discutidos em suas páginas, foi feita com a cabeça de quem obsessivamente procurava aprimorar sua própria interpretação de A montanha mágica.

Já nas primeiras páginas de Der Zauberberg - chamadas pelo seu autor de "Propósito" é possível identificar uma tentativa de elaboração estética ${ }^{3}$ da crise vivida na República de Weimar, na qual seu autor aponta as dificuldades em ser um narrador, este "[...] murmurante ${ }^{4}$ evocador do passado", em enfrentar a mudança histórica na qual a "pátina do tempo", a crosta que unia o presente ao passado, havia sido descascada, abrindo o espaço no qual se experimentava uma profunda mudança abissal [tief zerklüftende Wende]. É por esta razão que $A$ montanha mágica talvez seja uma obra tão ou até mais rica por suas preocupações formais do que outras obras, mais preocupadas em representar explicitamente a experiência da guerra, e não posso deixar de lamentar que Walter Benjamin, poucos anos depois, não a tenha sequer citado em seu famoso ensaio Experiência e pobreza. ${ }^{5}$

O tema do livro, como se anuncia logo em sua primeira linha, é "a história de Hans Castorp". ${ }^{6}$ É a história dele que "passou já há muito tempo", mesmo que esta distância não seja medida pelo tempo dos calendários. A construção da personagem, portanto, torna-se um problema balizado pelas possibilidades de se narrar em um tempo "[...] que mal acabou de começar". ${ }^{7}$ É por isto que pretendo me concentrar na caracterização de um "jovem simples", o que me permitirá, portanto, refletir sobre a "mudança abissal" expressa na literatura, e, quero crer, de maneira bastante eloquente através dos romances de formação.

E, dentre muitos dos insights de Moretti, me interessa sobretudo sua definição ${ }^{8}$ do Bildungsroman europeu do século XIX como a forma simbólica da modernidade representada através do jovem como protagonista. Moretti define a modernidade seguindo Marx, isto é, como "[...] uma revolução permanente que percebe a experiência acumulada pela tradição como um peso morto e que por isso não pode ser representada pela maturidade e muito menos pela velhice" ${ }^{\prime \prime}$ e que, portanto, encontraria na juventude, 
transitória por definição, sua forma correspondente. E esta experiência da juventude ficaria visível na própria caracterização ambivalente do Bildungsroman, baseada, segundo Moretti, nos princípios de classificação e transformação. ${ }^{10}$ Assim, os romances de formação poderiam ser caracterizados pela supressão do próprio ato de narrar em uma conclusão na qual o protagonista jovem chega a um acordo com um mundo que impusera limites aos seus anseios, alcançando uma síntese na qual o encantamento inicial e a decepção seguinte estabelecem uma solução de compromisso no seu final. Mas também o romance de formação pode rejeitar esta resolução, e, assim, a essência da história não estaria em seu fim, mas na sua narratividade, na apresentação de um processo inesgotável que o autor só pode encerrar de maneira arbitrária (e Stendhal, Pushkin, Balzac e Flaubert ilustrariam este caso), muitas vezes aniquilando seu personagem.

Os temas se encontram: narrar a história de um protagonista jovem é o tema do Bildungsroman do século XIX, mas permanece como um problema para Thomas Mann. Porém, mais do que um estudo escolástico sobre a permanência de um subgênero literário, me interessa pensar justamente no que seria uma nova sensibilidade histórica ${ }^{11}$ : como escrever um romance sobre a história de um jovem em um tempo que "mal acabou de começar"?

Mudanças sensíveis talvez não se deem somente entre o século XIX e o XX; é possível encontrá-las na obra do próprio Thomas Mann anterior à Primeira Guerra. Não consigo notar nada de semelhante a um personagem jovem como Hans Castorp em Os Buddenbrooks (onde a juventude está ausente, e, mais ainda, é impedida com a morte precoce de Hanno Buddenbrook), em Sua Alteza Real (onde o jovem príncipe Klaus Heinrich, por ser nobre, não precisa obedecer à exigência burguesa de desenvolvimento, transformação e progresso) ${ }^{12}$, e nem mesmo em Morte em Veneza, onde Tadzio, certamente bem mais novo do que Hans Castorp, é um símbolo atemporal de beleza. Tampouco nas pretensões artísticas de Tonio Kröger poderia notar algum esboço dos futuros contornos do despretensioso Castorp. Portanto, seria o protagonista de $A$ montanha mágica capaz de expressar a mesma força simbólica do típico personagem do romance de formação do XIX, no qual "o jovem é, por assim dizer, a 'essência' da modernidade, o sinal de um mundo que busca sentido mais no futuro do que no passado"? ${ }^{13}$ Talvez seja o caso de se perguntar se interessava a Hans Castorp buscar algum sentido.

\section{Mundo}

O homem não vive somente a sua vida individual; consciente ou inconscientemente participa também da vida de sua época e dos seus contemporâneos. Até mesmo uma pessoa inclinada a julgar absolutas e naturais as bases gerais e ultrapessoais da sua existência, e que da ideia de criticá-las permaneça tão distante quanto o bom Hans Castorp - até uma pessoa assim pode facilmente sentir o seu bem-estar moral um tanto diminuído pelos defeitos inerentes a essas bases. $O$ indivíduo pode visar numerosos 
objetivos pessoais, finalidades, esperanças, perspectivas, que the deem o impulso para grandes esforços e elevadas atividades; mas, quando o elemento impessoal que o rodeia, quando o próprio tempo, não obstante toda a agitação exterior, carece no fundo de esperanças e perspectivas, quando se lhe revela como desesperador, desorientado e falto de saída, e responde com um silêncio vazio à pergunta que se faz consciente ou inconscientemente, mas em todo caso se faz, a pergunta pelo sentido supremo, ultrapessoal e absoluto, de toda atividade e esforço - então se tornará inevitável, justamente entre as naturezas mais retas, o efeito paralisador desse estado de coisas, e esse efeito será capaz de ir além do domínio da alma e da moral, e de afetar a própria parte física e orgânica do indivíduo. Para um homem se dispor a empreender uma obra que ultrapassa a medida das absolutas necessidades, sem que a época saiba uma resposta satisfatória à pergunta "Para quê?", é indispensável ou um isolamento moral e uma independência, como raras vezes encontram e têm um quê heroico, ou então uma vitalidade muito robusta. Hans Castorp não possuía nem uma nem outra dessas qualidades, e portanto deve ser considerado medíocre, posto que num sentido inteiramente decoroso. ${ }^{14}$

Estas palavras do narrador de A montanha mágica lembram a definição de Georg Lukács do romance como forma do desterro transcendental, em que as estruturas da vida "[...] não portam em si a consagração do absoluto", e se calam quando já puderam dar "algum objetivo de modo imediato"15; mas, neste trecho do romance de Thomas Mann não há o conflito entre "objetivos pessoais, finalidades, esperanças, perspectivas" e um mundo impessoal, e, por isso, para Thomas Mann a narrativa da "vida individual", do desenvolvimento de uma interioridade constituída por sonhos frustrados, não será suficiente para a construção do seu protagonista. Portanto, mesmo um jovem despreocupado e medíocre será afetado pela crise das "bases absolutas", e mesmo que o personagem jamais tenha feito o esforço de se singularizar, de se diferenciar do mundo e do que o mundo dele espera ao pôr em questão as bases aparentemente naturais de sua vida, ele terá o impulso de começar a sua trajetória. No caso, uma narrativa a ser contada pelo autor.

A história começa com uma viagem, que, mesmo despretensiosa, é fruto da fadiga causada pelo excesso de trabalho. O autor decide iniciá-la quando Castorp sai em busca de repouso, pois, de alguma maneira, sua "parte física e orgânica" está debilitada. Temos, então, um jovem que deixa Hamburgo, sua cidade natal situada no norte da Alemanha, para ir até Davos, nos Alpes suíços, onde visitará seu primo Joachim Ziemssen, que tenta se curar de tuberculose no sanatório de Berghof. Neste trânsito, o narrador mostra como o espaço gera uma transformação no espírito de homens jovens, "pouco arraigados à vida"16, e que, por esta razão, "[...] chega até mesmo a transformar, num só golpe, um pedante ou um burguesote numa espécie de vagabundo". ${ }^{17}$ Assim, o romance apresenta aquele que é, para Franco Moretti, um dos traços mais marcantes dos romances de formação do XIX, nos quais os personagens se desenvolvem não mediante o lento aprendizado do ofício e das lições tradicionais paternas, mas a partir das incertezas e dos riscos da viagem, das aventuras e da boemia ${ }^{18}$, que possibilitarão ao jovem abandonar um repertório de referências cristalizadas para construir uma perspectiva a partir de uma experiência própria do mundo. 
Mas há, aqui, uma distinção paródica ${ }^{19}$ entre a motivação da viagem de Castorp e os desejos de mudança dos típicos protagonistas de romances do século anterior. Hans Castorp simplesmente não queria passar por aventuras e riscos, ainda que o espaço percorrido no trajeto de trem entre o norte da Alemanha e os Alpes suíços seja descrito como uma natureza cada vez mais hostil, na qual abismos e cumes se alternam perante os olhos de um apreensivo Hans Castorp, sua expectativa é a de que, uma vez instalado em Berghof, retomará a ordem no novo local de sua vida, ao qual se habituará sem dificuldades. ${ }^{20} \mathrm{Em}$ um primeiro momento, a transição é apenas um intervalo entre duas fases de repouso; de um lado, a disciplina do trabalho cotidiano; de outro, a monotonia da convalescença. Ele espera que o abismo da viagem seja novamente coberto pela rotina. Neste sentido, se se assemelha aos romances do XIX por ter na viagem um tópico central, por outro lado a decisão de viajar é inteiramente diferente da experimentada, por exemplo, por um Lucien de Rubempré, protagonista de Ilusões perdidas, cuja mudança para Paris é motivada por um forte desejo de afirmação de si. A vontade de mudar a própria vida é alheia a Hans Castorp.

Ele apenas embarca no trem para atender a um pedido de seu primo entediado e doente, já há cinco meses internado em Berghof, e como repousar por três semanas que se tornam sete anos - com o objetivo simples de se recuperar do esgotamento causado pelo trabalho. Estas duas motivações, bem menos pretensiosas do que a mudança para grandes capitais como Paris e Londres, revelam marcas bem características do personagem. Neste sentido, se as "bases ultrapessoais" já não escondem suas rachaduras, Hans Castorp ainda passeia sobre elas com naturalidade. Portanto, se no Bildungsroman do século XIX as pontes com o passado eram queimadas, Hans Castorp ainda as atravessa como se fossem inabaláveis. Neste sentido, é compreensível que Hans Castorp, ao chegar a Davos, seja recebido por uma figura familiar, o que me permite dizer que não temos exatamente um abandono voluntário das referências de origem, mas um deslocamento das mesmas que permite ainda a manutenção de um fiapo de relação entre Hamburgo e Davos. O encontro com Ziemssen, portanto, é uma visita a um parente, de modo que se torna necessário falar um pouco sobre o ambiente familiar do protagonista de $A$ montanha mágica, onde talvez seja possível encontrar alguns indícios desta atmosfera impessoal que delimita o mundo do personagem.

Talvez a principal marca da infância do protagonista seja o fato de ter se tornado órfão com apenas sete anos de idade; após a morte de seus pais, Hans Castorp esteve, por pouco mais de um ano, sob os cuidados de seu avô, Hans Lorenz Castorp, mas este breve tempo foi o suficiente para que o ancião, alguém que "[...] dificilmente se deixava abater" ${ }^{\prime 2}$, fosse um único e puído laço com o passado. O velho Castorp fascinava o menino e, em sua casa antiga, onde ainda se podia ouvir uma forma dialetal de alemão, era especialmente encantadora, aos olhos da criança, a pia batismal sobre a qual se deitavam as cabeças de Castorps há mais de duzentos anos. O narrador descreve o conjunto formado por uma bacia e uma bandeja de prata altamente oxidada, na qual se 
vê a crosta do passado, a pátina do tempo, símbolo de uma figura ancestral que "[...] sentia grande dificuldade de adaptar-se a inovações"22 e com a qual Hans Castorp se identificava, bem mais do que com seus pais. Mas dificilmente o velho lhe serviria de exemplo capaz de Ihe dar uma orientação para a vida; era, antes, o resquício de uma época inteiramente morta. Quando o narrador observa ironicamente ${ }^{23}$ que uma mosca pousa na testa - e ainda mexe as probóscides - do cadáver de Hans Lorenz Castorp durante um pomposo serviço fúnebre, ele sugere que a orfandade precoce é um traço marcante do protagonista de $A$ montanha mágica, como figura de uma experiência histórica.

Com a morte do ancião, Hans Castorp será tutelado pelo seu tio-avô, o cônsul Tienappel, cuja preocupação com o jovem órfão era exclusivamente administrativa. Dedicado apenas a gerenciar a herança de Castorp (da qual abatia uma quantia mensal para si, como forma de pagamento pelo seu trabalho), Tiennapel deixa frouxos os laços com o sobrinho-neto, a ponto de sequer criar a chance de um conflito capaz de provocar a possibilidade da transformação. Se há algo evitado no romance é a estratégia de identificação pela negação, sobretudo, pelo conflito de gerações. A única advertência de Tiennapel para Hans Castorp é a de que procurasse um emprego para manter seu refinado estilo de vida. O jovem decide se tornar engenheiro naval, escolha previsível no horizonte de uma cidade portuária como Hamburgo (mas também cultivado pelo gosto de Hans Castorp em desenhar navios) ${ }^{24}$, o que me permite pensar que ele era um homem, para utilizar uma expressão de Max Weber ${ }^{25}$, capaz de transitar sem desconforto pelo mundo desencantado, em que o trabalho técnico (como o de engenheiro naval) poderia ser aprendido por qualquer um, bastando para tal que o desejasse. $O$ passado figurado nas personagens familiares e no ambiente da cidade - não parece ser um fardo para Hans Castorp: "Confortavelmente e não sem dignidade, ele [Hans Castorp] carregou sobre os ombros a alta civilização". ${ }^{26}$ Dificilmente ele poderia ser um símbolo da modernidade, que deseja se libertar do peso que o passado lança sobre si. ${ }^{27}$ Se para muitos a civilização é um fardo, ou um conjunto de andrajos a ser despido, para Castorp, ela não deve ser nem rejeitada, nem esquecida - porque simplesmente ela, a civilização, não o incomodava.

Hans Castorp é, portanto, apresentado como uma "folha em branco". ${ }^{28}$ Sim, ele é uma folha em branco porque, se tivesse um papel político, poderia tanto se transformar em um conservador (dada a identificação com o avô), como em um progressista (por ser engenheiro, classicamente um ramo ligado ao progresso tecnológico). Mais ainda: ele é uma folha em branco porque, com seus vinte e três anos, não procura o conflito com o mundo, não quer conquistar sua autonomia pelo trabalho e, mesmo não sendo um desocupado, tem clara consciência de que prefere usufruir o seu tempo livre para fumar sua marca favorita de cigarro: "[...] o trabalho, em sua vida, servia apenas de obstáculo para o desfrute de Maria Mancini”. ${ }^{29}$ De fato, ele se sentia perfeitamente saudável apenas quando nada fazia. ${ }^{30}$ Daí, ser ele um personagem quase abstrato, parcialmente imune às identificações e projeções que poderiam ser lançadas sobre ele. Era, portanto, um 
homem "medíocre" 31 , sem que, conforme avisa o narrador do romance, este adjetivo duro carregue consigo um juízo negativo sobre a personagem. Logo, não identifico em Hans Castorp o "indivíduo problemático" em confronto com as contingências de um mundo instável ${ }^{32}$, mas também não creio que ele seja um indivíduo cujos objetivos são constituídos pelos valores herdados, e que, quando muito, encontra no mundo apenas alguns obstáculos para a sua realização, a não ser que acreditemos que estes valores herdados por Castorp pudessem ser enrolados em um cigarro "Maria Mancini”.

\section{Símbolo}

Mas chega o momento em que o corpo é afetado. A mediocridade de Hans Castorp, portanto, não é simplesmente a ausência de uma vontade de se impor no mundo; ela seria, também, a incapacidade de enfrentar a impessoalidade deste mundo, mais precisamente, a de se ser essencialmente órfão. E, assim, por mais que seja distinto de Wilhelm Meister, Julien Sorel e Lucien de Rubempré por não ter vontade de se perder em aventuras e enfrentar riscos, Hans Castorp não se sente confortável na rotina de seu trabalho, e, assim, se parece, caso sigamos Moretti ${ }^{33}$, com os protagonistas dos romances de formação do século XIX, os quais chegam a rejeitar qualquer tipo de trabalho. Por outro lado, seria apressado imaginar que Thomas Mann apresenta o cansaço de Hans Castorp da mesma forma como mostrara a melancolia e esgotamento de um comerciante diligente como Thomas Buddenbrook e as opressivas exigências que um escritor como Gustav von Aschenbach se impunha, pois Castorp não poderia perder algo que nunca teve: um ideal. É necessário, portanto, compreender o que significa a negação do esforço não como simples crítica boêmia do trabalho, mas como doença do corpo.

Pela voz do autor, poderíamos dizer que Hans Castorp não sente o peso que a civilização exerce em seus ombros; de modo algum é um personagem trágico, cujas ações se voltam contra si mesmo pela sua desmedida. Por ora, lembro-me do que Moretti diz a respeito da dissociação, nos romances de formação do século XIX, entre desenvolvimento individual e progresso histórico. Para ele - e aí Balzac é o caso mais paradigmático - o romance exerce uma clara função crítica, ao desfazer a ilusão de que o indivíduo evoluiria com o avanço social. Para Moretti, aprendemos na Comédia humana que a mudança é compulsória ${ }^{34}$, e o processo histórico progressivo simplesmente atropela e aniquila aqueles que o põem em movimento. Em A montanha mágica também se percebe um abismo entre um e outro, mas o livro mostra que ele se cava sob os pés mesmo daqueles que não desejam enfrentar o mundo. A crise, entendida como impessoalidade, não se manifesta somente ao frear a ambição individual, mas também ao paralisar o corpo do indivíduo, inclusive daquele capaz de se sentir absolutamente confortável consigo mesmo e com a sua circunstância. 
Como A montanha mágica começa com a viagem de um jovem em busca de repouso, poderia dizer: é a estagnação que se torna obrigatória - o que não deixa de ser uma curiosa e irônica inversão do "no início era a ação" [Am Anfang war die Tat], de Fausto, de Goethe. ${ }^{35}$ No caso de Hans Castorp, a estagnação, ao menos inicialmente, é uma aporia determinada pelo diagnóstico do Dr. Behrens, médico chefe do sanatório ${ }^{36}$ : às vésperas de seu retorno para Hamburgo (no final de sua inicialmente prevista estadia de três semanas), um febril Castorp se deixa examinar e ouve que, caso volte para a planície, ele fatalmente retornará a Berghof, pois a umidade de Hamburgo faria de uma inofensiva febre uma doença séria. Logo, ele ouve a forte recomendação para ficar por tempo indeterminado, para não correr o risco de adoecer gravemente. É uma situação constrangedora: se descer, ele retornará. Então, é melhor ficar de uma vez.

A despretensiosa viagem de Castorp para os Alpes, porém, mesmo que não o retire de sua mediocridade, ao menos gera um desconforto inicial. Curioso: adaptar-se ao cotidiano monótono do sanatório não seria problema para alguém caracterizado como bastante paciente ${ }^{37}$ e que leva apenas duas semanas para se distanciar de sua vida antes da viagem para Davos. ${ }^{38}$ Todavia, um mal estar, conforme vimos na passagem acima, se manifestava até mesmo em um jovem medíocre: já ao chegar em Berghof, Hans Castorp não se sente perfeitamente bem, tanto que seus queridos cigarros Maria Mancini passam a ter gosto de couro. ${ }^{39} \mathrm{O}$ mal estar de Hans Castorp se revela no mesmo corpo que acusa o incômodo de uma vida cuja fragilidade se abre mesmo para aqueles que jamais a questionam e a aceitam naturalmente. Castorp, um ser oco e sem substância, é efetivamente um corpo. É ele que, mediante as batidas mais aceleradas e intensas de seu coração, o avisa de sua paixão pela russa Clawdia Chauchat. ${ }^{40}$

A folha em branco é, portanto, somente um corpo, o que está em contraste com a concepção humanista ouvida na voz de Ludovico Settembrini, o intelectual italiano progressista e maçom que se atribui a tarefa de educar Hans Castorp. ${ }^{41}$ Para Settembrini, esta caricatura grotesca do iluminista, qualquer jovem seria antes uma folha totalmente escrita, cabendo ao pedagogo apenas apagar os borrões para chegar a uma imagem definida. Seriamente doente, Settembrini afirma que o jovem é uma forma neutra, ainda em definição $0^{42}$, e que, portanto, está sujeito a toda sorte de influências. A dúvida está em compartilhar da crença pedagógica de que ainda seja possível construir, em não perceber que a folha inteiramente rabiscada, esperando para ser burilada, está totalmente branca, isto é, não há mais trabalho prévio, não há mais herança nem mundo. Há um corpo, um corpo reprimido, que não faz questão de disfarçar seu pudor ao ouvir, pelas paredes finas do sanatório, o barulho feito pelo casal que ocupa o quarto ao lado. ${ }^{43}$ Será neste corpo reprimido, analisado por Dr. Krokowski, psicanalista do sanatório, que ocorrerá a luta entre as "potências da castidade e do amor" ${ }^{44}$, vencida pelas primeiras. Mas o prêmio será a doença, que, segundo o analista, é "amor transformado". ${ }^{45} \mathrm{~A}$ estagnação não é somente a aparente perda de tempo, a impossibilidade de produzir bens e riquezas, mas uma outra incapacidade: a de ser plenamente o que se é somente quando nos vemos em um outro, seja este outro uma ideia, uma pessoa, uma forma. 
Não deixa de ser irônico que um "burguesote" 46 como Castorp seja apenas um corpo, o que Ihe dá um perfil proletário (alguém que só tem sua força de trabalho para vender), e, mesmo que Thomas Mann não seja um marxista, a ironia não perde seu interesse, sobretudo, quando se sente a diferença entre este corpo abstrato e o corpo perfeito, ideal e inatingível de Tadzio, e o corpo puramente simbólico do príncipe Klaus Heinrich, no qual os súditos de Grimmburg se reconhecem e se rejubilam.

Hans Castorp, porém, não é o único jovem do romance; seu primo, Joachim Ziemssen, a quem jamais poderíamos atribuir o caráter de protagonista, serve-lhe de contraponto. Ao contrário de Castorp, Joachim sabe exatamente o que deseja da vida: a carreira militar. Mais ainda: se vê como um homem jovem, "estagnado como uma poça d'água" 47 há cinco meses nos Alpes, enquanto a "vida lá embaixo"48 progride e passa por mudanças decisivas. Seu juízo é o de um jovem que precisa se afirmar: "um ano tem um papel muito importante em nossa idade". ${ }^{49}$ Diferentemente de seu primo, que não opõe qualquer resistência à recomendação de Behrens para ficar em Berghof para evitar ser infectado, Ziemssen, cujo estado de saúde era bem mais preocupante do que o de Hans Castorp, desafia as ordens médicas de permanecer no sanatório, decidindo retomar sua vida profissional, sua verdadeira vocação, sabendo que as consequência seriam - como de fato acabaram sendo - fatais. E, em contraste com o corpo de Hans Castorp, o jovem militar exibe uma forma atlética apolínea, um corpo bem definido, ao mesmo tempo magro e musculoso $0^{50}$, mesmo que esta "magreza decente" esconda a tuberculose. Mas é em sua morte, descrita em uma das cenas mais tocantes - e irônicas - do romance, que o corpo de Joachim Ziemssen se revela como, talvez, jamais se revelasse em Hans Castorp. Em Ziemssen, o corpo não somente demonstra ser mais forte do que a vontade de viver e trabalhar ${ }^{51}$, mas é nele que o tempo de sua vida passa pelos anos que a doença não lhe permitira aproveitar. ${ }^{52}$

Com a morte, o rosto de Joachim reencontraria a "beleza de uma juventude viril". ${ }^{53}$ Será eternamente jovem porque jamais deixará de ser uma promessa para si mesmo, ainda que a morte the represente a cristalização de uma forma. Ser militar, no caso dele, não era ocasional: era um homem que se sentia bem vestindo um uniforme - muito parecido, a propósito, com outro grande personagem da literatura deste momento e, curiosamente, seu quase homônimo Joachim Pasenow, protagonista do primeiro volume da trilogia Os sonâmbulos, de Hermann Broch, um homem que, tal como Ziemssen, só encontra sentido na forma definida. ${ }^{54}$

O contraste entre a folha em branco e um homem uniformizado, entre um corpo abstrato, indefinido, e outro magro e musculoso, entre um civil sem ambições e um militar ansioso para participar de manobras e exercer sua profissão serve-me, justamente, para mostrar que o desenvolvimento de Hans Castorp - se é que ele passa por um desenvolvimento progressivo, linear e evolutivo - não é orientado pela busca de uma forma madura, adulta, definitiva. Ou seja: ser uma folha em branco significava, de um lado, ainda poder ser tudo, ser neutro, mas também significava não estar comprimido em um uniforme. 
Mas não seria justamente por ser exclusivamente um corpo que Hans Castorp genuinamente se envolveria pela primeira vez com algum assunto e se esforçaria em buscar um sentido, qualquer sentido, para as próprias experiências? Vivendo em meio a doentes, e ele mesmo constantemente febril, Castorp passa as noites de seu primeiro inverno em Berghof lendo livros de patologia e medicina em geral com o objetivo de buscar uma explicação sobre a vida, mais precisamente sobre o momento em que esta começa. Mas ainda é um interesse desencantado: o corpo dele é o corpo humano e universal, abstrato em toda sua complexidade orgânica. É o corpo dele, como poderia ser de qualquer outro homem. E, ao contrário dos organismos inferiores - aprende Hans Castorp - que exercem todas as suas atividades vitais pela sua superfície, os organismos superiores sempre escondem sua essência, ocultam o momento em que se originam, e se fragmentam em cada vez mais divisões e subdivisões de sua matéria: "parecia vedado à vida compreender-se a si própria. A maioria dos processos bioquímicos não eram somente desconhecidos, como também era inerente à sua natureza esquivar-se à compreensão". ${ }^{55}$ Hans Castorp tem consciência da finitude a partir do momento em que a vida lhe permanecerá incompreensível, muito embora este momento de compreensão já houvesse sido anunciado quando, durante um exame para verificar a causa de sua febre, Castorp vê o esqueleto de sua mão pelo aparelho de raio$X$ do sanatório. É "a imagem de si mesmo no túmulo" ${ }^{56}$ que se revela por meios técnicos, frios, abstratos. Seu esqueleto é uma armação totalmente desprovida de carne. A única coisa reconhecível é o anel herdado do avô.

Seu interesse por medicina e seu deslumbramento com a técnica servem para marcar o momento em que ele se dá conta de que, na verdade, ele poderia ter sido médico. Ou seja: para Castorp, mais do que pensar em um futuro diferente, ele imagina que seu passado poderia ter sido outro, e de que ele se tornara engenheiro por mero acaso. ${ }^{57}$ Enfim: mesmo que tal consciência tenha sido despertada pela técnica, a medicina difere significativamente da engenharia ao ser motivo do interesse do nosso herói. Hans Castorp sabe que o seu passado, a partir daquele momento, nada Ihe significava. Mais do que isso: desperta nele o impulso amoroso, de saída de si, em que ele consegue se ver de outra forma (seja no Raio-X, seja em um passado alternativo), desnaturalizando sua trajetória pessoal. É o amor que - aprende Castorp com a palestra de Krokowski se não for assumido, se permanecer mudo, torna-se doença. ${ }^{58}$

Ser uma folha em branco, portanto, não deve necessariamente ser interpretado como um defeito incorrigível. Se Hans Castorp a princípio nada quer, posteriormente ele passa a se interessar por algum assunto, ainda que o interesse esteja confinado a uma ciência especializada, como é o caso da medicina. Mas nota-se a presença do desejo do conhecimento. ${ }^{59}$

A aprendizagem, todavia, não se revela científica, mas estética, na medida em que variam as maneiras como Hans Castorp sente e percebe o mundo, desde o simples prazer em fumar, até o elaborado problema filosófico e poético que está no coração do 
romance: "o tempo é o elemento da narrativa, assim como é o elemento da vida; está inseparavelmente ligado a ela, como aos corpos no espaço. É também o elemento da música, que o mede e subdivide, carregando-o de interesse e tornando-o precioso". ${ }^{60} \mathrm{E}$ aí volto ao tema inicial apresentado pelo autor de $A$ montanha mágica no prólogo, e recuperado pelo mesmo no início do último capítulo: o problema da narrativa, que, para ele, dá conteúdo ao tempo, da mesma forma que a música o faz. E como a história é a história de Hans Castorp, penso que não seria demais pensar o seu desenvolvimento a partir de suas impressões estéticas e contatos com diversas formas de obras de arte. Um sinal expressivo está no final do romance, quando, em uma conversa com sua amada Clawdia Chauchat, Hans Castorp diz que não teria para quem escrever cartas, nem mesmo para seus parentes em Hamburgo. E ele diz, citando uma bela canção de Gustav Mahler, que se desvencilhara do mundo [Ich bin der Welt abhand gekommen]. ${ }^{61}$ Se o mundo saiu de si, é porque, de alguma forma, o seu efeito paralisante se desfez. Ver-se representado no corpo, mesmo em uma máquina, é um passo para o esboço de seu perfil, para a precisão do contorno de sua forma.

Mais do que apontar para a admiração de Thomas Mann por Gustav Mahler, talvez fosse interessante investigar esta frase de Hans Castorp como um indício eloquente para tentar compreender como o personagem começa a deixar de ser uma folha em branco. Ele também está "mal acabando de começar". Certamente este perfil não seria marcado simplesmente como uma diferença antagônica em relação ao mundo - mesmo porque, conforme o título da canção de Mahler, ele parece ter se despedido deste. Não há em Castorp uma afirmação voluntarista de si mesmo - a conquista de uma liberdade, no sentido do século XIX - mas isto não o impediria de deixar sua passividade absoluta, de deixar de ser uma "folha em branco". Como bem disse Eckhard Heftrich, a grandeza de Hans Castorp, sua "genialidade", não estaria em sua "[...] produtividade, mas na capacidade de se espantar e de manifestar curiosidade, ou seja, de estar aberto". ${ }^{62}$ Ele não perde a capacidade de se encantar. Mesmo porque a passividade nunca havia predominado completamente em Hans Castorp; não temos, no romance, qualquer guinada redentora. De modo que talvez Hans Castorp jamais tenha sido uma perfeita nulidade, o que explica sua decorosa mediocridade. Afinal, como foi percebido por Hermann Weigand ${ }^{63}$, mesmo a sua quase irrefletida e indiferente decisão de se tornar engenheiro naval guardava, em si, algo de próprio: Castorp, afinal, quando criança, gostava de desenhar navios.

Na escolha quase apática de sua profissão, já estava presente uma inclinação estética. O mesmo se poderia dizer sobre seu interesse pelo corpo, que, em um primeiro momento, é um conhecimento técnico, despersonalizado e desencantado, vendo o mundo mediante aparelhos de Raio- $X^{64}$ e explicações sobre a estrutura celular de organismos superiores, mas, também, desde a sua infância, igualmente dirigido para a representação da figura humana e para sua dimensão simbólica, sendo marcante a 
lembrança do retrato pintado de Hans Lorenz Castorp, que se confundiria posteriormente com a imagem definitiva de seu avô. ${ }^{65}$ Da mesma maneira, já em Berghof, ele também aprecia o quadro de Clawdia Chauchat pintado por Behrens. O médico, dedicado ao pincel enquanto não cuidava e debochava de seus pacientes tuberculosos, comenta com Castorp que conhecia bem a russa, mas de maneira subcutânea, ou seja, sua pressão arterial, seus tecidos, seu sistema linfático, etc. Mas, segundo o médico, na verdade era "[...] a superfície que oferecia as maiores dificuldades". ${ }^{66}$ Hans Castorp se encantara com o retrato por ser possível até mesmo "ver os poros" 67 da pele russa representada amadoristicamente por Behrens - este tendo sido o ponto de partida para que ele começasse a ler avidamente livros de medicina.

Mais do que através de estruturas orgânicas complexas, infinitamente subdivididas, é também na simples aparência que o corpo revela-se misterioso. Não é só a análise biológica que desperta o interesse de Hans Castorp, que também terá em mãos $A$ miséria da condição humana, uma obra de Inocêncio III, emprestada por Leo Naphta, o antagonista de Settembrini. Ao mesmo tempo jesuíta e comunista, defensor do terror revolucionário e da cultura medieval, Naphta mantém em sua habitação uma escultura do século XIV, uma Pietá de autoria anônima em que o corpo de Cristo é representado de maneira inteiramente desproporcional segundo os critérios anatômicos objetivos ${ }^{68}$, mas ainda assim capaz de impressionar o jovem. Afinal, se o corpo é uma organização sofisticada, ele também se revela deformado, sofredor e débili ${ }^{69}$, mas, acima de tudo, o que o espantava era o elemento simbólico na religião: para Hans Castorp, mais do que as missas regulares, os funerais ofereceriam, pela sua cerimônia e pela sua inevitável compostura, mais possibilidades para edificar a alma. ${ }^{70}$

O seu interesse artístico se reflete e se projeta inicialmente em corpos pintados e esculpidos. ${ }^{71}$ Mas as artes plásticas, diz o narrador ao seu leitor, se mostram de uma só $v^{v e z}{ }^{72}$, ao contrário do drama, seja ele de gosto clássico - como no teatro - ou de entretenimento de massa, como o cinema ${ }^{73}$, ambos fontes de prazer para Hans Castorp. Don Carlos, uma peça de Friedrich Schiller, é constantemente lembrada por Castorp por representar uma forma exemplar de comportamento digno perante a morte: "Parece-me que o mundo e a vida foram feitos de sorte que deveríamos sempre andar de preto, com uma golhilha engomada em lugar de colarinho [...] recordando-nos da morte". ${ }^{74} \mathrm{~A}$ arte o leva, juntamente com Joachim, a fazer visitas aos moribundos do sanatório, o que possivelmente dá ao subcapítulo seu título de Totentanz ("Dança dos mortos", ou, como na tradução de Herbert Caro, "Dança macabra"); e, aconselhado por Behrens, Castorp e seu primo conhecem Karen Karstedt, doente que mora fora de Berghof, a quem levam ao cinema, onde os três se divertem com "uma vida apresentada aos pedacinhos, divertida e apressada, cheia de uma inquietação saltitante" ${ }^{75}$, na qual se exibia meticulosamente um filme ${ }^{76}$ cuja história fala de volúpia, de nudez e libido. ${ }^{77}$ Mas em quase todas as artes Hans Castorp experimenta o corpo a partir de representações, sejam elas estáticas ou dinâmicas. A arte o retira de sua passividade quase absoluta; se o corpo fora o motivo da estagnação, também será de objeto de encantamento. 
O romance, porém, não me parece ser uma narrativa da evolução do personagem. Sim, por um lado, Castorp sai de um estado de estagnação e desencantamento do mundo técnico e administrado rumo a um crescente encantamento estético, e, neste sentido, percorre o caminho inverso de personagens do romance de formação do século XIX, como Wilhelm Meister ou Pip (de Grandes esperanças, obra de Charles Dickens) que partem de expectativas impossíveis para um compromisso com um mundo que impõe um limite para seus ideais, sob a pena de serem destruídos por este mesmo mundo. Mas se no século XIX o personagem jovem, após se desencantar, ou se resignava ou se destruía, isto não significa que o caminho oposto percorrido por Hans Castorp o salvará. A capacidade de se encantar com corpos e formas alheias conhece um limite no conhecimento da forma e do corpo quando este corre o risco de se desintegrar e, aquela, de se dissolver.

No capítulo "Neve", Castorp adquire consciência do corpo, mas desta vez de seu próprio corpo, e não por meio de um conhecimento científico abstrato, obtido através dos livros de medicina, ou de uma imagem do corpo esculpido, pintado ou projetado em uma tela de cinema. Decidido a fazer um passeio de esqui nos Alpes, o nosso herói acaba por se perder em meio a uma nevasca que o transporta para um lugar de absoluto silêncio e monstruosa indiferença da natureza, capaz de assustar - encantar? - um filho da civilização. ${ }^{78}$ Paradoxalmente, a neve, que tudo encobre, revela para Hans Castorp sua pura condição corporal; cada vez mais envolvido pela agressividade da natureza, Castorp perde a noção de segurança e autopreservação, e the resta apenas um resquício de lucidez, que o lembra de como a doença não é só algo que gera dor, mas retira também a capacidade de senti-la. Há um embotamento. ${ }^{79}$ É um momento raro no romance, diria que é a guinada de Castorp, o momento em que este passa a falar consigo mesmo, sem intermediações ${ }^{80}$, sozinho em meio a uma imensa paisagem branca, desvencilhado do mundo, como liricamente se pode ouvir na canção de Mahler. Aí reside sua liberdade, tão bem descrita pelo narrador: "atrás dele, não se encontrava nenhum caminho ao qual ele se ligava; atrás dele, nada havia que pudesse reconduzi-lo ao ponto de onde veio". ${ }^{81}$

Todavia, a ameaça da morte efetivamente se dá quando Hans Castorp, no final do romance, decide lutar nas trincheiras da Guerra. O último capítulo reserva apenas algumas páginas para os momentos em que o narrador se despede de seu personagem; se antes, segundo Moretti, as histórias terminavam abruptamente, com o fim contingencial e violento de suas personagens, em A montanha mágica é o protagonista quem sobrevive à narrativa, pois sua provável morte teria se dado somente após o fim da narrativa. No campo de batalha, ele murmura uma outra canção, desta vez "A Tília" [Der Lindenbaum] de Franz Schubert, criada em cima de um poema de Wilhelm Müller. 
Hans Castorp se encantara com a canção ainda em Berghof, ao ouvi-la em um disco tocado no gramofone comprado pela gerência do sanatório. Aqui, borram-se as divisões entre arte e técnica, entre encantamento e desencantamento, quando Castorp, desde menino um apreciador de música, se entrega aos prazeres propiciados pela magnífica invenção tecnológica, capaz de lhe permitir uma experiência estética renovada e cuidadosa, a ponto de ele zelar pela coleção de discos do sanatório, sobretudo, por aqueles que mais aprecia. É nas madrugadas em que ele, sozinho, passa a "ter consciência do 'significado' do seu amor e do objeto amado" 82 : a morte. Mas a morte aqui não é simplesmente a morte biológica, mas uma morte semanticamente oposta à vida por não preservar formas, mas dissolvê-las, por ser a canção precisamente uma arte que, do corpo, retira somente a voz para compor seu material poético ${ }^{83}$, levando a um "[...] triunfo sobre o próprio eu" ${ }^{84}$, atingindo, assim, a "essência do amor". ${ }^{85}$

Luca Crescenzi é convincente ao dizer que Hans Castorp se educa a partir da visão, cuja finalidade seria "[...] a descoberta das formas sugestivas que a morte assumia na vida". ${ }^{86}$ E ele tem razão: é a lembrança do avô morto no caixão que se confunde com a de um quadro, é a imagem em Raio-X, é o corpo de Cristo, são as cenas de Don Carlos... todas estas representações são diferentes representações da morte. Da mesma maneira, é agudo ao notar que a música se diferencia das demais artes ao "viver além da forma". ${ }^{87}$ Mas creio que é necessário ainda pensar um pouco mais a respeito. "Valia a pena morrer por essa canção mágica", conta o narrador, falando pela consciência de Hans Castorp. Mas por quê? É nela que se unem "mundo, símbolo e amor". ${ }^{88} \mathrm{O}$ mundo inicial de Hans Castorp, uma folha em branco, essencialmente órfão, é aquele que ele carrega nos ombros sem the sentir o peso, mas que também o paralisaria. Ele era uma folha em branco porque poderia ser tudo e não tinha um horizonte de possibilidades que 0 definisse. Será a paralisia que o levará a simbolizar, seja por uma máquina de Raio-X e por livros de medicina, seja por um quadro amador, por uma Pietá medieval, por uma peça de Schiller ou por um filme, e, assim, a consciência apenas parcial de que sempre admirara corpos e formas, se revela lentamente no sanatório. E quando ouve a canção de Schubert, ele sai de si, ele ama ao ter a experiência da dissolução da forma, e seu reencontro com a planície se dá em meio a obuses, lama e corpos despedaçados; se deixa de viver de maneira estagnada, ele se reconcilia com um mundo em destruição, bem diferente daquele que carregava nos ombros sem fardo, nem peso, e que nada the caracterizava. Talvez pela primeira vez, nos principais textos de Thomas Mann até então, arte e ação estejam juntos, afinal, o tempo da narrativa (e da música) correspondem ao tempo da vida. ${ }^{89} \mathrm{Em}$ Os Buddenbrooks, Sua Alteza Real, Morte em Veneza e Tonio Kröger, o apelo simbólico é rejeitado de diferentes maneiras ${ }^{90}$, expressando uma necessária divisão entre o homem e o mundo, que pode ser vista até mesmo como condição para a própria atividade artística (o que salta aos olhos de maneira quase didática e programática em Tonio Kröger). Lembrando uma das mais belas passagens de Os Buddenbrooks, o senador sente que, quando há forma, não há mais a vida que a gerou: "Esses sinais exteriores precisam de tempo para chegar, assim como a luz duma dessas estrelas, ali em cima, da qual não sabemos se não já está se apagando quando o 
seu brilho nos parece mais claro". ${ }^{91}$ A canção de Schubert, se é símbolo, certamente não o é como foi para Joachim Ziemssen seu uniforme, que o veste mesmo após a morte em uma sessão espírita em Berghof, e, muito menos, como é a imagem imóvel do avô de Hans Castorp, fixada para sempre em um retrato. ${ }^{92}$ Se antes as formas assumiam a aparência da eternidade da morte, exterior a quem a observa, agora ela se origina no próprio corpo do qual sai uma voz, se transformado em uma canção fugidia.

Se Hans Castorp possuiria algum caminho próprio, seria o de simplesmente seguir sua formação não como amadurecimento manifesto em um acordo com o mundo, mas, sim, de sentir, com "escrúpulos de consciência" 93 e "semipensamentos intuitivos" ${ }^{94}$, os limites do mundo como forma, como Bild, não sem antes descobri-los e experimentá-los, para depois, transcendê-los, murmurando uma música durante uma batalha.

Ora, a beleza da cena, o impacto de imaginar um jovem soldado cantando, bem baixinho, versos de uma música romântica quase pueril, enquanto a morte o rodeia de todas as formas, me faz pensar em como as páginas finais do romance aliam magia (da canção) e técnica (das armas). Em todo o romance, arte e técnica talvez tenham estado próximas, mas nunca tão entrelaçadas; havia magia nos desenhos de navio de um garoto quase programado para ser engenheiro; assim como havia a tecnologia dos gramofones na audição de suas músicas favoritas; Castorp não foi educado por Tienappel, mas administrado; seu desinteresse refletia o desinteresse da técnica, que não se pergunta o porquê de sua utilização; mas é ela também que lhe dá a consciência de sua finitude, ao "antecipar o trabalho de decomposição". Não que a arte tenha conduzido ideologicamente Hans Castorp para a guerra - esta é uma interpretação corrente sobre os ditos efeitos negativos do romantismo no século $X X^{95}$ - mas talvez porque, ao contrário de resignados como Wilhelm Meister e Pip e autodestrutivos como Lucien de Rubempré, Castorp agisse não somente pelo prazer. ${ }^{96}$

\footnotetext{
* Pedro Caldas é professor adjunto do Departamento de História da UniRio.

Este artigo foi possível graças ao financiamento de Bolsa de Produtividade em Pesquisa do CNPq.

${ }^{1}$ MORETTI, F. The Way of the World: The Bildungsroman in European Culture. London: Verso, 1987.

2 Deixo aqui algumas referências importantes para o leitor interessado em se aprofundar no assunto. JACOBS, J. Wilhelm Meister und seine Brüder: Untersuchungen zum deutschen Bildungsroman. München: Wilhelm Fink, 1972; MAAS, W. P.. O Cânone mínimo: O Bildungsroman na história da literatura. São Paulo: Editora UNESP, 2000; MAZZARI, M. V. Labirintos da aprendizagem: Pacto fáustico, romance de formação e outros temas de literatura comparada. São Paulo: Ed.34, 2010; SELBMANN, R. Der Deutsche Bildungsroman. Stuttgart: Metzler, 1994, 2a.ed.

${ }^{3}$ Ao ler o texto da conferência de Hans-Robert Jauss sobre experiência estética, consegui identificar que, nas primeiras páginas d'A montanha mágica se encontravam as três grandes dimensões da experiência estética (ao menos como a definiu Jauss), a saber, a poiesis, a
} 
katharsis e a aisthesis. Cf. JAUSS, H.-R. Pequeña apologia de la experiencia estética. Barcelona: Paidós, 2002. A poeisis estaria presente no que Mann expõe como a tarefa do narrador após a Guerra; a aisthesis se notaria na própria estrutura da percepção do leitor, que, segundo o autor do romance, precisaria de mais do que sete dias e até mesmo sete meses para apreciar a história de Hans Castorp; a katharsis, por sua vez, é também um tema do romance a partir do momento em que lembra das dificuldades em se criar uma identificação entre a história e o leitor após a Primeira Guerra Mundial ("um tempo que mal acabou de começar"). Cf. MANN, T. [1924] Der Zauberberg: Roman. Grosse komentierte Frankfurter Ausgabe. Frankfurt am Main: Fischer, 2002, pp. 9-10.

${ }^{4}$ Neste caso, me permito discordar da solução encontrada por Herbert Caro na excepcional tradução de Der Zauberberg para nossa língua. Caro simplesmente omitiu da frase "raunenden Beschwörer des Imperfekts" descrever o narrador como um "mago evocador do passado", quando o verbo raunen pode também querer dizer murmurar. $E$ entre silêncio e evocação há uma diferença.

${ }^{5}$ Vale a pena mencionar a admiração de Walter Benjamin pelo romance, expressa em carta a Gershom Scholem em abril de 1925, o que contrastava com a profunda antipatia anterior do filósofo por Thomas Mann, marcado pelas posições políticas registradas no conservador Betrachtungen eines Unpolitischen, seu ensaio escrito durante a Primeira Guerra Mundial. Cf. BENJAMIN, W. Briefe I. Edição organizada por G. Scholem e T. W. Adorno. Frankfurt am Main: Suhrkamp, 1978, p. 377 apud NEUMANN, M. Der Zauberberg: Kommentarband. Grosse komentierte Frankfurter Ausgabe. Frankfurt am Main: Fischer, 2002, pp. 113-114.

${ }^{6}$ MANN, T. [1924] Der Zauberberg. Op. cit., p. 9.

${ }^{7}$ Ibidem, pp. 10-11.

${ }^{8}$ Cf. MORETTI, F. The Way of the World. Op. cit., pp. 8-10.

${ }^{9}$ Ibidem, p. 5.

${ }^{10}$ Estes conceitos foram, segundo Moretti, assumidamente retirados de Lotman. Cf. Ibidem, p. 7.

${ }^{11}$ Para ver as maneiras como a palavra Bildung aparece no romance, cf. SCHARFSCHWERDT, J. Thomas Mann und der deutsche Bildungsroman: Eine Untersuchung zu den Problemen einer literarischen Tradition. Stuttgart; Berlin; Köln; Mainz: W.Kohlhammer, 1967, pp. 146-149. Um breve e competente resumo sobre a discussão se $A$ montanha mágica seria um romance de formação pode ser encontrado em: NEUMANN, M. "Ein Bildungsweg in der Retorte: Hans Castorp auf dem Zauberberg". In: Thomas Mann Jahrbuch, Bd. 10, 1997, pp. 133-135.

12 Jürgen Scharfschwerdt analisa as variações na relação de Thomas Mann com o gênero Bildungsroman de maneira bastante precisa, ainda que por vezes algo dependente do recurso da intencionalidade autoral, documentada a partir de ensaios, cartas e diários de Thomas Mann. Mas sua análise da trajetória do romance de formação, que sairia do esgotamento (em Os Buddenbrooks), passaria pela reafirmação (em Sua Alteza Real) e chegaria à renovação pela paródia (em A montanha mágica), é bastante densa e merece ser conhecida pelo interessado no tema. Cf. SCHARFSCHWERDT, J. Op. cit.,, caps. I e III.

${ }^{13}$ MORETTI, F. Op. cit., p. 5.

${ }^{14}$ MANN, T. A montanha mágica. Tradução de Herbert Caro. Rio de Janeiro: Nova Fronteira, 2000, pp. 47-48. Na edição no original em alemão, pp. 53-54. Grifo meu.

${ }^{15}$ LUKÁCS, G. A teoria do romance: Um ensaio histórico-filosófico sobre as grandes formas da épica. São Paulo: Ed. 34, p. 62.

${ }^{16}$ MANN, T. [1924] Der Zauberberg: Roman. Op. cit., p. 12.

17 Ibidem, p.10

${ }^{18}$ Cf. MORETTI, F.Op. cit., p. 5. 
${ }^{19}$ Além de Scharfschwerdt, o estudo de Manfred Sera também compreende A montanha mágica como paródia do romance de formação. Cf. SERA, M. Utopie und Parodie bei Musil, Broch und Thomas Mann: Der Mann ohne Eigenschaftten - Die Schlafwandler - Der Zauberberg. Bonn: Bouvier, 1969.

${ }^{20}$ MANN, T. [1924] Der Zauberberg. Op. cit., p. 13.

${ }^{21}$ Cf. MANN, T. A montanha mágica. Op. cit., p. 31.

22 Ibidem, p. 36.

${ }^{23}$ MANN, T. [1924] Der Zauberberg.Op. cit., pp. 46-47.

${ }^{24}$ Cf. WEIGAND, H. J. [1933] The Magic Mountain: A Study of Thomas Mann's Novel Der Zauberberg. Chapel Hill: The University of North Carolina, 1965, p. 33.

${ }^{25}$ Cf. WEBER, M. "Ciência como vocação". In: Metodologia das ciências sociais. Vol. 2. São Paulo: Cortez; Campinas: Unicamp, 2001, p. 439.

${ }^{26}$ MANN, T. [1924] Der Zauberberg: Roman. Op. cit., p. 51.

${ }^{27}$ Cf. MORETTI, F. Op. cit., p. 5.

${ }^{28}$ MANN, T. [1924] Der Zauberberg. Op. cit., p. 59.

${ }^{29}$ Ibidem, p.57. Sobre o tema do trabalho como um possível leitmotiv do romance, ver: HEFTRICH, E. Zauberbergmusik: Über Thomas Mann. Frankfurt am Main: Vittorio Klostermann, 1975, pp. 5764.

${ }^{30}$ Cf. MANN, T. [1924] Der Zauberberg. Op. cit., p. 94

31 Ibidem, p.53

${ }^{32}$ LUKÁCS, G. Op. cit., p. 79.

${ }^{33}$ MANN, T. Der Zauberberg. Op. cit., p. 165.

${ }^{34}$ Cf. MORETTI, F. Op. cit., p. 163.

${ }^{35}$ Cf. GOETHE, J. W. Fausto I. São Paulo: Editora 34, 2011, p. 112.

${ }^{36}$ Cf. MANN, T. Der Zauberberg. Op. cit., pp. 276-277.

${ }^{37}$ Ibidem, pp. 159.

${ }^{38}$ Cf. Ibidem, p. 226.

${ }^{39}$ Cf. Ibidem, pp. 93-94.

${ }^{40}$ Cf. Ibidem, p. 215.

${ }^{41}$ Cf. Ibldem, p. 154.

${ }^{42}$ Cf. Ibidem, pp. 305-306.

${ }^{43}$ Cf. Ibidem, pp. 61-63.

${ }^{44}$ MANN, T. A montanha mágica. Op. cit., p. 176.

${ }^{45}$ Ibidem, p. 177.

${ }^{46}$ Para uma visão sobre a construção de personagens burgueses, ver o estudo clássico de Georg Lukács (já marxista) sobre Thomas Mann. LUKÁCS, G. "A la busqueda del burgues". In: Thomas Mann. Barcelona: Grijalbo, 1969.

${ }^{47}$ MANN, T. Der Zauberberg. Op. cit., p. 29. 
${ }^{48}$ Ibidem.

49 Ibidem.

${ }^{50}$ Cf. Ibidem, p. 331.

${ }^{51}$ Cf. Ibidem, p. 753; cf. WEIGAND, H. J. [1933]. Op. cit., p. 53.

${ }^{52}$ Cf. MANN, T. Der Zauberberg. Op. cit., pp. 810-811.

${ }^{53}$ Ibidem.

${ }^{54}$ Manfred Sera comparou de maneira interessante A montanha mágica e os três livros de Os sonâmbulos. Escapou-lhe, porém, a semelhança que ressaltei aqui entre os dois "Joachims" talvez porque Pasenow tenha uma importância como protagonista jamais desempenhada por Ziemssen.

${ }^{55}$ MANN, T. A montanha mágica. Op. cit., p. 384.

${ }^{56}$ Cf. MANN, T. Der Zauberberg. Op. cit., pp. 332-333.

${ }^{57}$ Cf. Ibidem, pp. 398-399.

${ }^{58}$ Cf. Ibidem, p. 196. Uma análise interessante sobre a relação entre amor e doença no romance foi feita por E. Heftrich. Cf. Op. cit., p. 78.

${ }^{59}$ Daí a indagação simples, porém certeira, de Joseph Lawrence: "se Hans Castorp é o recipiente de uma educação filosófica, deve ser possível determinar o que há para ser aprendido" Cf. LAWRENCE, Joseph P. "Transfiguration in Silence: Hans Castorp's Uncanny Awakening". In: DOWDEN, S. (org.) A Companion to Thomas Mann's The Magic Mountain. Rochester: Camden House, 2002, p. 3.

${ }^{60}$ MANN, T. A montanha mágica. Op. cit., p. 739.

${ }^{61}$ Cf. MANN, T.. Der Zauberberg. Op. cit., pp. 898-899. A letra de Ich bin der Welt abhand gekommen é um poema de Friedrich Rückert, e faz parte do ciclo "Rückert Lieder", um conjunto de cinco canções criado na primeira década do século $X X$ - antes, portanto, do início da redação de $A$ montanha mágica.

${ }^{62}$ HEFTRICH, E. Op. cit. p. 208.

${ }^{63}$ Cf. WEIGAND, H. J. [1933]. Op. cit., p. 33.

${ }^{64}$ Uma boa análise sobre a importância da tecnologia em A montanha mágica, especificamente do Raio-X, foi feita por Karla Schultz, que demonstra como a consciência que Hans Castorp adquire de si mesmo passa pela sua visão técnica do mundo. Todavia, creio que esta visão técnica também se relaciona com uma experiência estética de Castorp. Cf. SCHULTZ, K. "Technology as Desire: X-Ray Vision in The Magic Mountain". In: DOWDEN, S. D. (org.). A Companion to Thomas Mann's The Magic Mountain. Rochester: Camden House, 2002, $2^{\mathrm{a}}$.ed.

${ }^{65}$ Cf. MANN, T. Der Zauberberg. Op. cit., pp. 42-44.

${ }^{66}$ Ibidem, p. 390.

${ }^{67}$ Ibidem, p. 391.

${ }^{68}$ Cf. Ibidem, p. 535.

${ }^{69}$ Cf. Ibidem, p. 594.

${ }^{70}$ Ibidem, p. 168.

${ }^{71}$ Cf. REED, T. J. Thomas Mann: The Uses of Tradition. Oxford: Clarendon Press, 2a.ed, 1996, p. 254.

${ }^{72}$ Cf. MANN, T. Der Zauberberg. Op. cit., p. 816. 
${ }^{73}$ Cf. SERA, M. Op. cit., p. 190.

${ }^{74}$ MANN, T. A montanha nágica. Op. cit., p. 403.

${ }^{75}$ Ibidem, p. 432.

${ }^{76}$ Segundo Michael Neumann, o filme em questão é Sumurun, de Ernst Lubitsch, a que Thomas Mann assistiu em 1920. O autor certamente não se importou com o anacronismo de colocar seus personagens para verem um filme que seria produzido somente após a Grande Guerra. Cf. MANN, T. Der Zauberberg - Kommentarband. Frankfurt am Main: Fischer, 2002, p. 240.

${ }^{77}$ Cf. MANN, T. A montanha mágica. Op. cit., p. 433.

${ }^{78}$ Cf. MANN, T. Der Zauberberg. Op. cit., pp. 717-718.

${ }^{79}$ Cf. Ibidem, p. 730.

${ }^{80}$ Hermann Weigand percebe como Hans Castorp atravessa, ao longo do romance, uma série de crises que paulatinamente lhe dão consciência de si, servindo-lhe de caminho pedagógico. Mas a moralidade de Castorp, segundo Weigand - e é isto que lhe ensinam as crises - é a de se deixar levar até o ponto da desmedida, da hybris. Não sei se concordo integralmente com a tese, ainda que a crescente importância da arte para Hans Castorp, de alguma maneira, seja sempre também uma condução para além dos limites da forma, do corpo. Mas definitivamente não vejo como poderíamos chamar, tal como Weigand faz, Castorp de "gênio". Cf. WEIGAND, H. J. [1933]. Op. cit., pp. 21-24. Em outro momento, igualmente feliz, Weigand demonstra como Castorp adquire consciência de sua própria personalidade, e, mais, de seu próprio percurso, durante um diálogo com sua amada Clawdia Chauchat. Cf. Ibidem, p. 135.

${ }^{81}$ MANN, T. A montanha mágica. Op. cit., p.724.

82 Ibidem, p.896.

${ }^{83}$ Para análises interessantes que tratam da importância formativa da música para a construção de Hans Castorp como personagem: Cf. REED, T. J. Op. cit. pp. 266-274; SERA, M. Op. cit., pp. 154155.

${ }^{84}$ MANN, T. A montanha mágica. Op. cit., p. 899.

${ }^{85}$ Ibidem.

${ }^{86}$ CRESCENZI, L. Melancolia occidentale: La montagna magica di Thomas Mann. Roma: Carocci, 2011 , p. 143.

${ }^{87}$ Ibidem, p. 228.

${ }^{88}$ MANN, T. A montanha mágica. Op. cit., p. 897.

${ }^{89}$ Cf. Ibidem, p. 739.

${ }^{90}$ Cf. SERA, M. Op. cit., p.134. Para Manfred Sera, este ceticismo perante a forma simbólica seria muito claro nas obras de Broch e Musil.

${ }^{91}$ MANN, T. Os Buddenbrooks: Decadência de uma família. Rio de Janeiro: Nova Fronteira, 2000, p. 471.

${ }^{92}$ Cf. CRESCENZI, L. Op. cit., p. 125. Embora Crescenzi afirme que Hans Castorp seja um gênio melancólico justamente por ser capaz de dar um sentido exterior e atemporal ao mundo (no que divirjo inteiramente), suas considerações foram fundamentais para que eu chegasse a tal interpretação.

${ }^{93}$ MANN, T. A montanha mágica. Op. cit., p. 897.

${ }^{94}$ Ibidem, p. 899. 
${ }_{95}$ Um exemplo deste tipo de interpretação se encontra em EKSTEINS, M. A Sagração da Primavera: A Grande Guerra e o nascimento da era moderna. Rio de Janeiro: Rocco, 1992.

${ }^{96}$ Retirei esta expressão de uma cena inicial de Fanny e Alexander, filme de Ingmar Bergman, no qual o teatro de marionetes de Alexander aparece com uma inscrição: "Não somente pelo prazer". 